\title{
Effect of Diode Power Losses on the Operation of Boost Converter System
}

\author{
Soha M. Abd El-Azeem ${ }^{(1)}$, S.M. El-Ghanam ${ }^{(1)}$,M. Ismail ${ }^{(1)}$, F.A.S. Soliman ${ }^{(2)}$ and S.A. Kamh $^{(1)}$ \\ 1- Electronic Res. Lab (E.R.L)., Faculty of Women for Arst, Science, and Education, Ain Shams Univ., \\ Cairo, Egypt. \\ 2- Nuclear Materials Authority, P. O. Box 530-Maadi, Maadi, Cairo, Egypt.
}

\begin{abstract}
The paper presents a study on the effect of diode power losses on the operation of 5/24.4 VDC boost converter based on MOSFET switch type STP36NF06. In this concern, a comparative study between the system performances in the discontinuous conduction mode was carried out whenever; MBRS130LT3G Schottky diode and FR101 fast recovery diode were applied. It was found that, the boost converter output voltage was 20.0 Volts with voltage ripple of 1.4 Volts, using MBRS130LT3G Schottky diode. Moreover, the output voltage reached 18.6 Volts with voltage ripple of 1.6 Volts, whenever FR101 fast recovery diode was used. On the other hand, the peak ringing voltage and parasitic ringing values at the switch node were 4.8 Volts and $454 \mathrm{kHz}$, respectively applying Schottky diode. While, their values were 8.0 Volts and $463.1 \mathrm{kHz}$ applying fast recovery diode.
\end{abstract}

Keywords: Boost converter system, discontinuous conduction mode, MOSFET switch, Schottky diode and fast recovery diode.

\subsection{Introduction}

In most DC-DC converter topologies, power diodes tend to be responsible for a part of power losses; conduction and switching losses that reduce their efficiency. Conduction loss is generated in the forward voltage of the diodes and its on-state resistance, whereas the switching loss is generated as result of reverse recovery charge in the bulk material and the diode junction. To maximize efficiency of DC-DC converters, it requires decreasing power loss in power diodes (P. Haaf, and J. Harper, 2007, S. Abdel-Rahman, et al, 2014). In this concern, the present paper is a trail to shed further light on the effect of diode reverse recovery and forward voltage on the performance of the DC-DC boost converter system.

\subsection{Diode Power Losses}

\subsubsection{Conduction loss}

Conduction loss is generated in the forward voltage of the diodes and its on-state resistance (B.P. Singh, 2016, R. Bürkel and Th. Schneider, 1999). Graphically, the on-state resistance can be determined from the (I-V) characteristic curve of a diode (Fig. 1). Where, the diode forward voltage $\left(\mathrm{V}_{\mathrm{F}}\right)$ is related to the on-state resistance ( $\left.\mathrm{r}_{\mathrm{on}}\right)$ according to Eq. (1). 


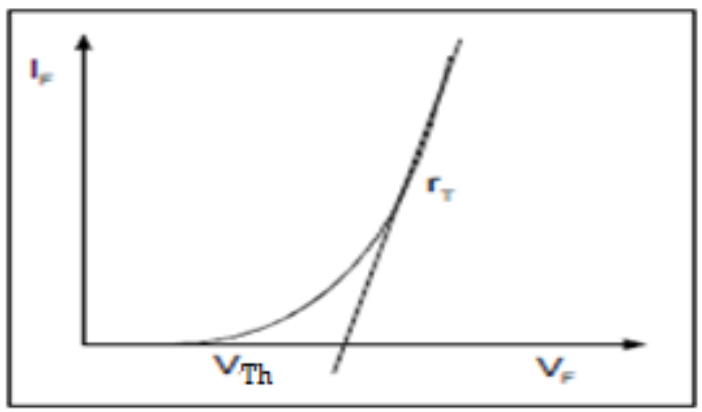

Fig. (1): (I-V) characteristic curve of diode showing the on-state resistance.

$$
V_{F}=V_{T h}+I_{F} r_{o n}
$$

Furthermore, the diode power dissipation $\left(\mathrm{P}_{\mathrm{D}}\right)$ could be calculated according to Eq. (2).

$$
P_{D}=V_{T h} I_{F}+r_{o n} I_{F}^{2}
$$

Where:

$\mathrm{V}_{\mathrm{Th}}$ : Threshold voltage, $\mathrm{I}_{\mathrm{F}}$ : Forward current.

\subsubsection{Switching losses}

Diode switching loss is generated as a result of the reverse recovery charge in the bulk material and the diode pn junction [N. Krihely and S. Ben-Yaakov, 2010, R.W. Erickson 2015].

\section{- Reverse recovery effect of diode}

The current in a forward-biased junction diode is buildup of majority and minority carriers. When the forward current of a forward conducting diode has been reduced to zero, small current will continue to conduct for some small time after due to minority carriers stored in the pnjunction and bulk semiconductor material. These minority carriers require some finite time called the reverse recovery time $\left(\mathrm{t}_{\mathrm{rr}}\right)$, to recombine with oppositely charges to be neutralized (M. $\mathrm{H}$. Rashid, 2014 and C.M. Cheh, 2016). In this concern, there are two reverse recovery characteristics; namely: soft recovery and abrupt recovery (Fig. 2). 


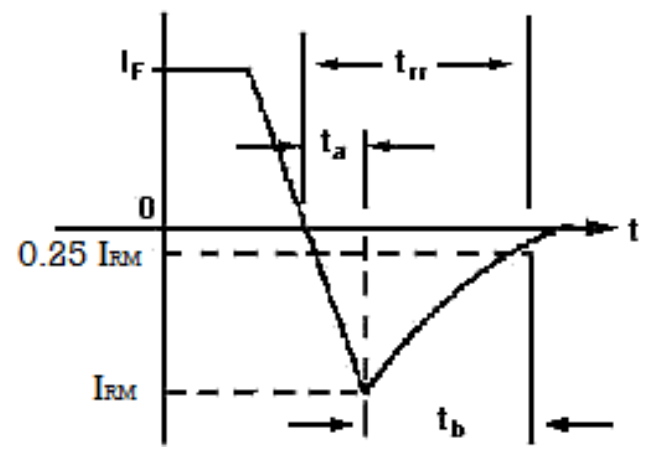

(a)

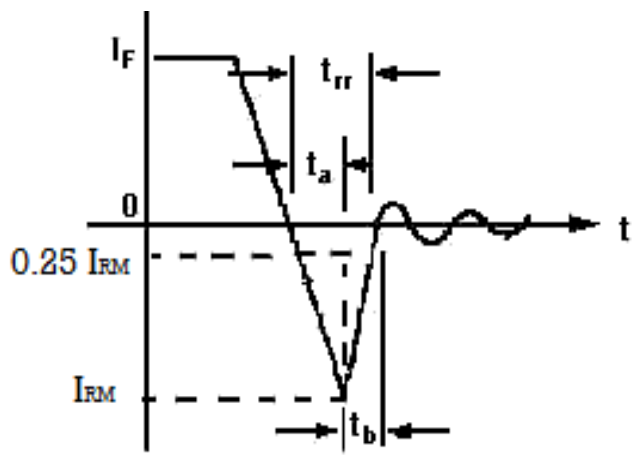

(b)

Fig. (2): Reverse recovery characteristics of diodes (a: soft recovery and b: abrupt recovery).

The abrupt reverse recovery if responsible for producing extremely high current rating (di/dt) which produces large voltage spikes across any stray inductances that are in series with the diode (B. J. Baliga,2008). When dealing with abrupt reverse recovery, the softness factor (SF) is $\leq 1$, snubber circuit is required, whereas, SF is $>1$ for soft recovery.

As shown in Fig. (2), $\mathrm{I}_{\mathrm{RM}}$ is defined as the maximum reverse recovery current and could be calculated applying Eq. (3).

Where:

$$
I_{R M}=t_{a} \frac{d i}{d t}
$$

Where:

$\mathrm{t}_{\mathrm{a}}$ : Rise time,

$\mathrm{t}_{\mathrm{b}}$ : Storage time, and

$\mathrm{t}_{\mathrm{rr}}$ : Reverse recovery time.

The magnitude of $t_{r r}$ depends on:

1. Junction temperature,

2. Forward current,

3. Rate of forward current fall $\left(\mathrm{dI}_{\mathrm{f}} / \mathrm{dt}\right)$,

Where;

$$
\mathrm{t}_{\mathrm{rr}}=\mathrm{t}_{\mathrm{a}}+\mathrm{t}_{\mathrm{b}}
$$

SF: Softness factor, Ratio of $t_{b} / t_{a}$.

Where;

$$
S F=\frac{t_{b}}{t_{a}}
$$




\section{- Reverse recovery charge}

The reverse recovery charge $\left(\mathrm{Q}_{\mathrm{RR}}\right)$ is the amount of charge carriers that flow across the diode in the reverse direction due to changeover from forward conduction to reverse blocking condition. Its value is determined from the area enclosed by the path of the reverse recovery current. That is:

$$
\begin{aligned}
& Q_{R R}=\frac{1}{2} I_{R M} \boldsymbol{t}_{a}+\frac{1}{2} \boldsymbol{I}_{R M} \boldsymbol{t}_{b}=\frac{1}{2} \boldsymbol{I}_{R M} \boldsymbol{t}_{r r} \\
& I_{R M}=\frac{2 Q_{R R}}{t_{r r}}
\end{aligned}
$$

From equations (4) and (5) one gets;

$$
I_{R M}=\frac{2 Q_{R R}}{t_{r r}}=\boldsymbol{t}_{a} \frac{d \boldsymbol{i}}{d \boldsymbol{t}}
$$

If $t_{b}$ is negligible in comparison to $t_{a}$, then:

$$
\boldsymbol{t}_{r r}=\boldsymbol{t}_{a}
$$

Hence equation (7) becomes;

$$
t_{r r}=\sqrt{\frac{2 Q_{R R}}{d i / d t} .}
$$

and,

$$
I_{R M}=\frac{2 Q_{R R}}{t_{r r}}=\sqrt{2 Q_{R R} \frac{d i}{d t}}
$$

From the previously mentioned losses, the present paper is a trial to shed further light on the problem and introduces insight on the selection of the adequate boost diode. Practical examples are presented to assist selection of component that control ringing production.

\subsection{Experimental Procedures}

\subsection{Boost converter design}

The design, implementation, operation and efficiency evaluation of a DC-DC boost converter system operating in discontinuous conduction mode was investigated for circuit diode. The designed circuit needs to compile the following requirements; input voltage $\left(\mathrm{V}_{\text {in }}\right)=5.0$ Volts, output voltage $\left(\mathrm{V}_{\mathrm{o}}\right)=24.4$ Volts, switching frequency $\left(\mathrm{f}_{\mathrm{s}}\right)=2.0 \mathrm{kHz}$, duty cycle $(\mathrm{D})=50 \%$ 
and voltage ripple $\left(\mathrm{V}_{\text {ripple }}=0.625\right.$ Volt. Based on the required $\mathrm{V}$ ripple, the output capacitor $\left(\mathrm{C}_{\mathrm{o}}\right)$ was selected. The standard values of coil inductance $(\mathrm{L})$, output capacitor, load resistance $\left(\mathrm{R}_{\mathrm{L}}\right)$ and input capacitor $\left(\mathrm{C}_{\mathrm{in}}\right)$ were calculated (T. Eichhorn, 2008) using Eqs. (12 and 13) and is illustrated in Table (1).

$$
\begin{aligned}
& \text { Vo }=\frac{1}{2}\left[1+\sqrt{1+\frac{2 R_{L} D^{2}}{f_{s} L}}\right] V_{i n} \\
& C_{o} \geq \frac{I_{o}\left(1-\sqrt{\frac{2 L}{R_{L} T_{s}}}\right)}{f_{s} V_{\text {ripple }}} \cdots . .
\end{aligned}
$$

Where;

$\mathrm{I}_{\mathrm{o}}$ : Output current, and

$\mathrm{T}_{\mathrm{s}}$ : Switching time.

Table. (1): Calculated circuit elements and parameters of boost converter system.

\begin{tabular}{|cc|cccc|}
\hline $\mathbf{L}, \boldsymbol{\mu H}$ & $\mathbf{C}_{\mathbf{0}, \boldsymbol{\mu} \mathbf{F}}$ & $\mathbf{C}_{\mathbf{i n}, \boldsymbol{\mu} \mathbf{F}}$ & $\mathbf{R}_{\mathrm{L}}, \boldsymbol{\Omega}$ & Input current, $\mathbf{A}$ & Input power, W \\
$\mathbf{3 3 0}$ & 100 & 100 & 100 & 1.89 & 9.45 \\
\hline
\end{tabular}

Figure (3) shows the circuit diagram of boost converter design based on the previously suppositions and calculations. On the other hand, experimental investigation has been carried out to analyze the circuit parameters variations under different power switches.

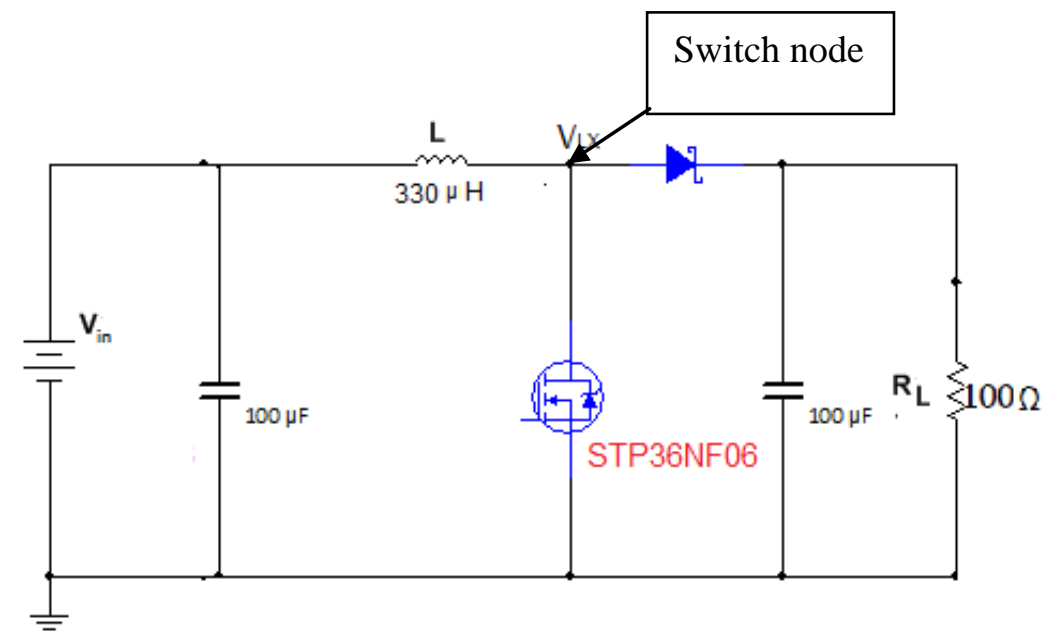

Fig. (3): Boost converter circuit.

Furthermore, Table (2) illustrates the voltage and current rating of the used MOSFET switch. 
Table (2): Voltage and current rating of MOSFET switch.

\begin{tabular}{|cc|} 
Parameter & STP36NF06 MOSFET Switch \\
\hline Breakdown voltage, $\mathbf{V}$ & 60 \\
\hline Current rating, $\mathbf{A}$ & 19.5 \\
\hline
\end{tabular}

\subsection{Diode selection}

During the boost converter design, FR101 fast recovery and MBRS130LTG Schottky silicon diodes have been introduced. The matter is mainly due to the suitability of their voltage and current rating (B. Hauke, 2014). Where, their forward current $\left(\mathrm{I}_{\mathrm{F}}\right)$ was measured to be $1.61 \mathrm{~A}$ and $0.7 \mathrm{~A}$, respectively. On the other hand, their breakdown voltage $\left(\mathrm{V}_{\mathrm{RM}}\right)$ was 50 Volts and 30 Volts.

\subsection{Results and Discussions}

\subsection{Reverse recovery characteristics of diodes}

The reverse recovery characteristics of fast recovery-and Schottky - diodes are shown in Fig. (4). From which, one can found that, the storage $\left(t_{a}\right)$ and rise time $\left(t_{b}\right)$ has been measured to be $53.5 \mathrm{~ns}$ and $98.2 \mathrm{~ns}$, respectively for fast recovery diode. On the other hand, for Schottky diode $t_{\mathrm{a}}$ and $\mathrm{t}_{\mathrm{b}}$ are measured to be $53.5 \mathrm{~ns}$ and $70.06 \mathrm{~ns}$, respectively. The reverse recovery time $\left(t_{\mathrm{rr}}\right)$ for both devices was calculated using Eq. (4). It was found that, its value for fast recovery diode equal $151.7 \mathrm{~ns}$ and $123.5 \mathrm{~ns}$ for Schottky diode. Also, for fast recovery diode, the maximum reverse recovery current was measured to be $37 \mathrm{~mA}$. From which, the total reverse recovery charge $\left(\mathrm{Q}_{\mathrm{RR}}\right)$ was calculated to be $2.8 \mathrm{nC}$. Concerning, Schottky diode, the maximum reverse recovery current and the total reverse recovery charge were $20 \mathrm{~mA}$ and $1.23 \mathrm{nC}$, respectively.

The work was extended to calculate the softness factor (SF). Where, it was found that, the reverse recovery phenomena of two devices were soft recovery. This is mainly due to that, the values of SF equal 1.83 and 1.31 for fast recovery and Schottky diode, respectively, i.e SF >1. From the previous results, it is clearly shown that, the reverse recovery charge of Schottky diode is much less than that of fast recovery ones, it is attributed to the junction capacitance and slightly dependent on the reverse current rating (di/dt) as there is no excessive minority carriers (M. H. Rashid, 2014). 


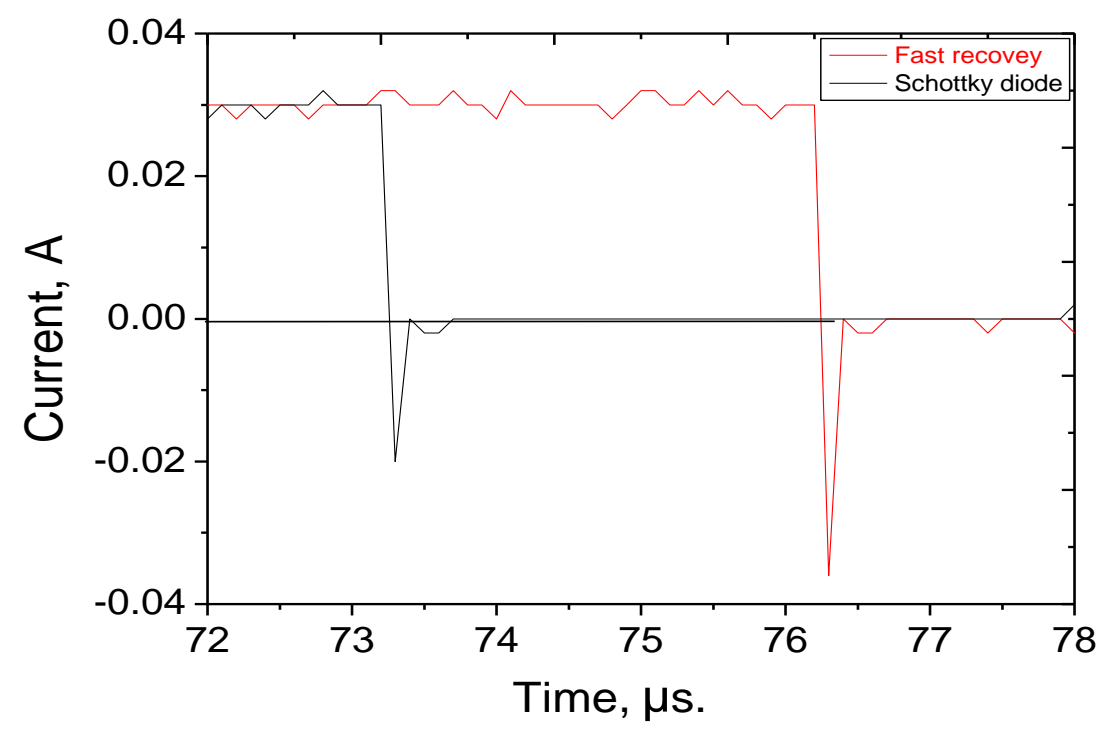

Fig. (4): Reverse recovery characteristics of fast recovery - and Schottky -diodes.

For more confirmation of the obtained results, the reverse recovery characteristics of both diodes were simulated, plotted and a comparison between the experimental - and simulated results were performed as shown in Fig. (5), and finally, Table (3) illustrates the detailed results.

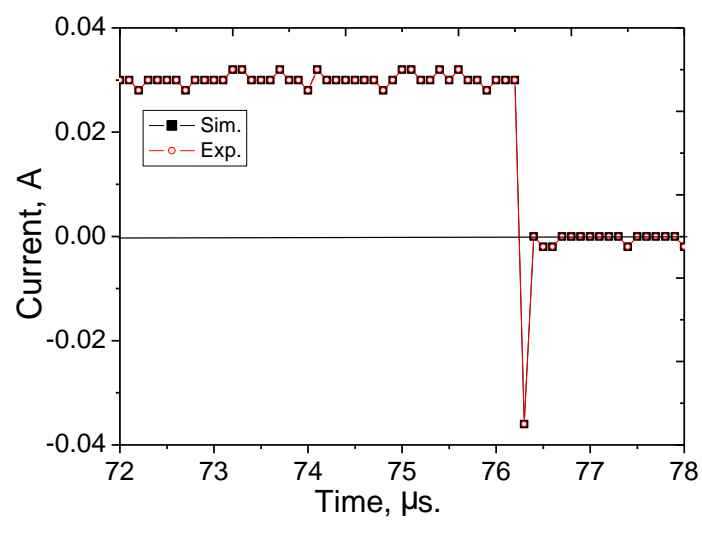

(a)

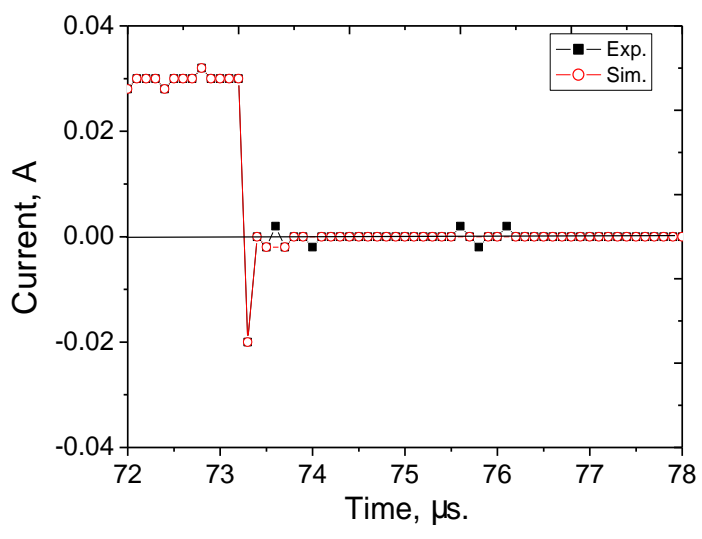

(b)

Fig. (5): Experimental and Simulated reverse recovery characteristics of (a) fast recovery- and (b) Schottky silicon diodes. 
Table (3): Summery of the reverse recovery characteristics of fast recovery- and Schottky-diodes.

\begin{tabular}{|c|cccc|}
\hline Electrical parameter & \multicolumn{3}{c|}{ Diodes } \\
& \multicolumn{3}{|c|}{ Fast recovery } & \multicolumn{2}{c|}{ Schottky } \\
\cline { 2 - 5 } & Sim. & Exp. & Sim. & Exp. \\
\hline Storage time $\left(\mathbf{t}_{\mathbf{a}}\right), \mathbf{n s}$ & $\mathbf{5 0}$ & $\mathbf{5 3 . 5}$ & $\mathbf{5 3}$ & $\mathbf{5 3 . 5}$ \\
\hline Rise time $\left(\mathbf{t}_{\mathbf{b}}\right), \mathbf{n s}$ & 101 & $\mathbf{9 8 . 2}$ & $\mathbf{7 0}$ & $\mathbf{7 0 . 6}$ \\
\hline Reverse recovery time $\left(\mathbf{t}_{\mathbf{r r}}\right), \mathbf{n s}$ & 151 & 151.7 & 123 & 123.5 \\
\hline Reverse recovery charge $\left(\mathbf{Q}_{\mathbf{r r}}\right), \mathbf{n C}$ & $\mathbf{2 . 7 9}$ & 2.8 & 1.23 & 1.23 \\
\hline Maximum reverse recovery current $\left(\mathbf{I}_{\mathbf{R M}}\right), \mathbf{m A}$ & 37 & 37 & 20 & 20 \\
\hline Softness factor $(\mathbf{S F})$ & 2.02 & 1.83 & 1.32 & 1.31 \\
\hline
\end{tabular}

\subsection{Design and testing of boost converter system 3.2.1 Switch node ringing}

As an important matter when constructing boost converter circuit, it is necessary to consider the ringing voltage at switch node as its maximum value $\left(\mathrm{V}_{\mathrm{pk}}\right)$ mustn't exceeds the

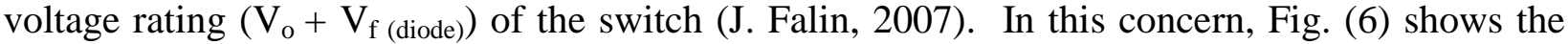
parasitic ringing measured at time scale of $5.0 \mu$ s showing the ringing voltage on applying fast recovery and Schottky diode. From which one found that, $\mathrm{V}_{\mathrm{pk}}$ was measured to be 8.0 Volts at parasitic ringing frequency $\left(f_{p}\right)$ of $463.1 \mathrm{kHz}$ and 4.8 Volts at $454 \mathrm{kHz}$, respectively.

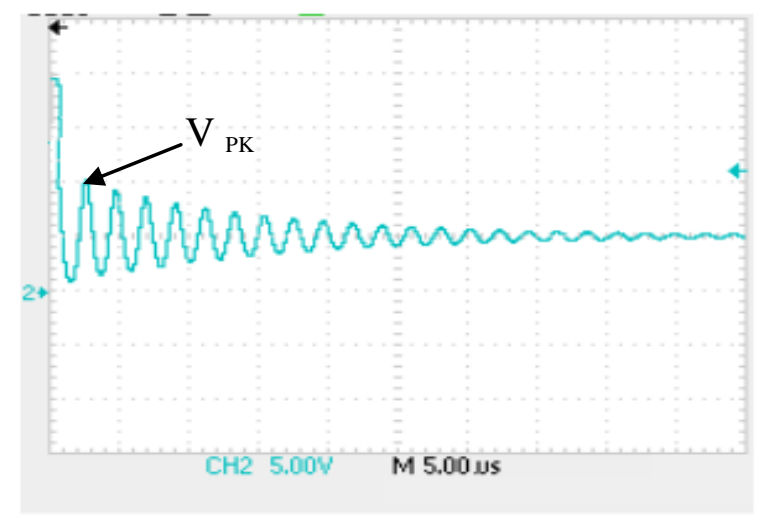

(a)

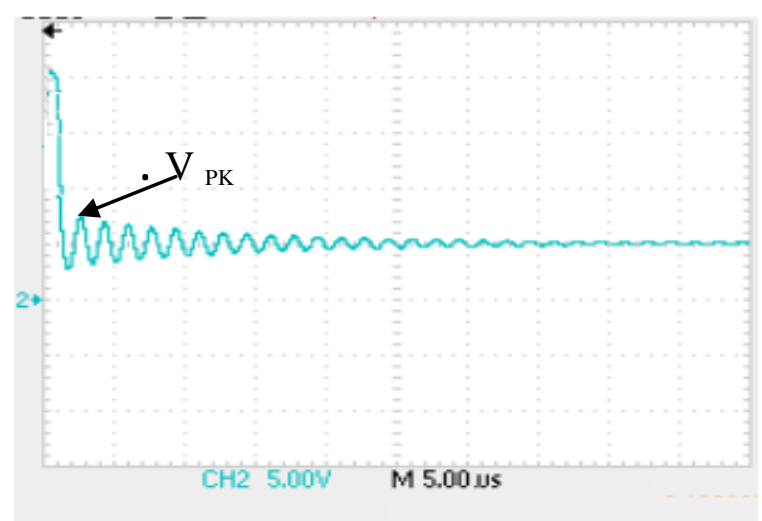

(b)

Fig. (6): Waveform of output voltage signal at switch node, showing the parasitic ringing for fast recovery and (b) Schottky diode.

\subsubsection{Spike voltage}

Moreover, the spike voltage $\left(\mathrm{V}_{\text {spike }}\right)$, during the turn-off conditions was plotted and analyzed. From which, $\mathrm{V}_{\text {spike }}$ values were calculated, for both the fast recovery - and Schottky diode, to be 1.0 and 0.8 Volt, respectively (Fig. 7). 


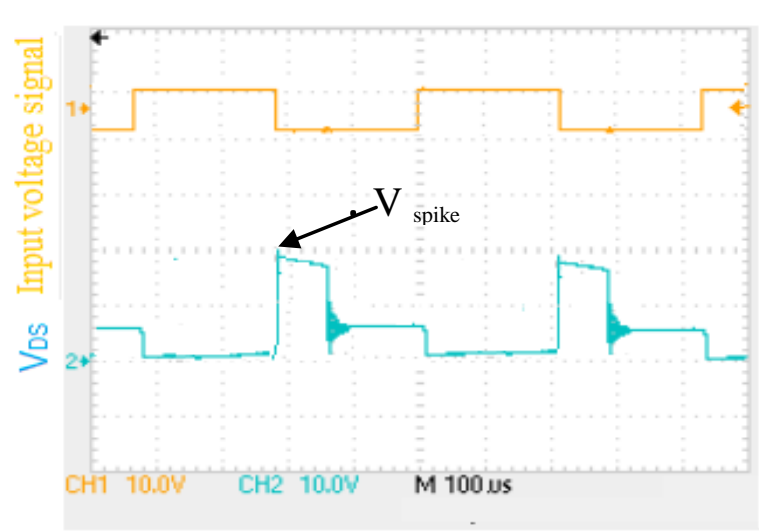

(a)

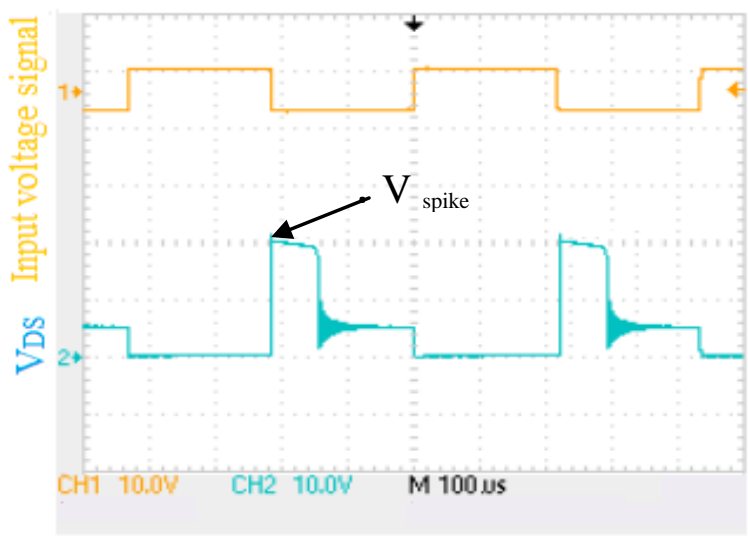

(b)

Fig. (7): Input voltage signal waveforms, and output voltage signal at switch node for (a) fast recovery and (b) Schottky diode.

\subsubsection{Output voltage}

A snapshot of input voltage signal and the DC output voltage of the boost converter showing voltage ripple is shown in Fig. (8). It is clearly shown that, for the case of fast recovery diode $\mathrm{V}_{\mathrm{o}}$ was measured to be 18.6 Volts. On the other hand, whenever applying Schottky diode $\mathrm{V}_{\mathrm{o}}$ stepped up to 20.0 Volts.

Voltage ripple is one of the most critical problems affecting the performance of power electronic circuits as a whole. So, the work was extended to measure $\mathrm{V}_{\text {ripple }}$ superimposed on the DC output voltage of the boost converter system. Referring to Fig. (8), it is found that, $V_{\text {ripple was }}$ measured to be 1.6 Volts whenever fast recovery is used and stepped down to 1.2 Volts for case of Schottky diode.

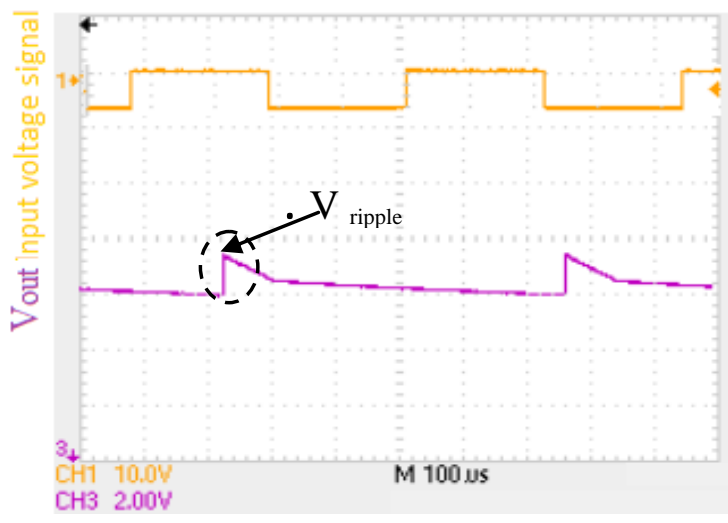

(a)

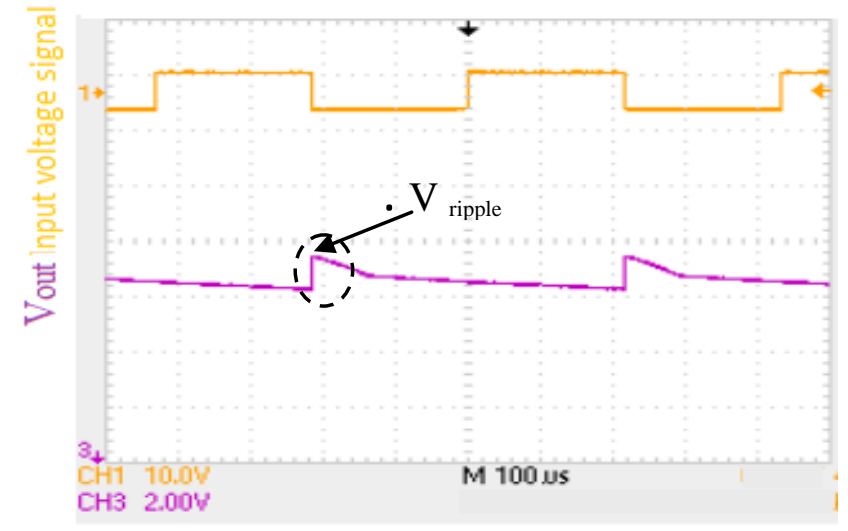

(b)

Fig. (8): Input voltage signal waveforms and dc-output voltage of boost converter showing the voltage ripple for (a) fast recovery and (b) Schottky diode. 


\section{Conclusions}

Due to the high importance of DC-DC boost converters in the world of electronics up to date, the present paper was concerned with a comparative study between the performance of Schottky and fast recovery diodes during the operation of such systems. In this concern, DC-DC boost converter operating in discontinuous conduction mode was designed, implemented and tested based on Schottky and fast recovery diodes. From the experimental work, results and analysis, it could be concluded that: High efficiency boost converter system: low power loss, low electromagnetic interference, low voltage ripple superimposed on the DC output voltage was achieved whenever the system based on Schottky diode rather than the fast recovery ones.

\section{References}

B. Hauke," Basic Calculation of a Boost Converter's Power Stage“, Application Note, SLVA372C, Texas Instrument, 2009-2014.

B. J. Baliga, “Fundamentals of Power Semiconductor Devices”, Ch.5, p.262, Springer, USA, 2008.

B.P. Singh, "Electronic Devices and Integrated Circuits“, 1st Ed., Ch.3, Dorling Kindersley, Pvt. Ltd., India, pp. 107- 135, 2006.

C.M. Cheh, " The Impacts of Platinum Diffusion to the Reverse Recovery Lifetime of a High Power Diode Devices”, MATEC Web of Conferences, No. 78, pp.1-7, 2016.

J. Falin, "Minimizing Ringing at the Switch Node of a Boost Converter," Application Report, Texas Instrument, SLVA255, 2006

M. H. Rashid, "Power Electronics: Devices, Circuits, and Applications", 4th Ed., Ch.2, Courier Westford, USA, pp. 65- 87, 2014.

N. Krihely and S. Ben-Yaakov, "Modeling and Evaluation of Diode Reverse Recovery in Discrete-Transition Simulators", IEEE, pp. 4514- 4520, 2010.

P. Haaf, and J. Harper, "Understanding Diode Reverse Recovery and its Effect on Switching Losses“, Fairchild Semiconductor, pp. A23-A33, 2007. www.fairchildsemi.com.

R. Bürkel and Th. Schneider,“ Fast Recovery Epitaxial Diodes (FRED) ",CharacteristicsApplications-Examples, IXYS, p.12, 1999.

R.W. Erickson, "Fundamentals of Power Electronics“, Ch.4, Lecture 11, ECEN 4797/5797, pp. 1- 22, 2015. 
S. Abdel-Rahman, et al, "PFC Boost Converter Design Guide“, Application Note, Infineon Technologies AG, pp. 1-29, 2014.

T. Eichhorn, "Boost Converter Efficiency through Accurate Calculations", Senior Applications Engineer, Jour. of Power Electronics Technology, pp. 30-35, 2008.

\section{الملخص العربى}

ثلثثير الطاقة المفقودة من النبيطة الثنائية ذات القدرة على آداء نظام المحول الإكترونى الرافع للجهد

سها محمد عبد العظيم (1)ـ صفاء محمد رشدى الغنام (1) منال إسماعيل مرسى (1) فؤاد عبد المنعم سعد سليمان(2) وثناء عبد التواب قمح(1)

1 ـ ـ معمل أبحاث الإكترونياتـ قسم الفيزياءـ كلية البنات للأداب والعوم والتربيةـ جامعة عين شمس- القاهرة- جمهورية مصر العربية

r - هيئة المواد النوويةـ ص ب. 530 - المعادى- 11728- القاهرة- جمهورية مصر العربية

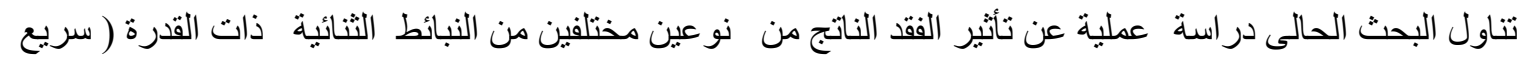
التعافى من الطر از

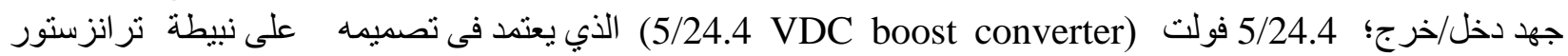
تأثير المجال الأكسيدى المعنى من الطر از

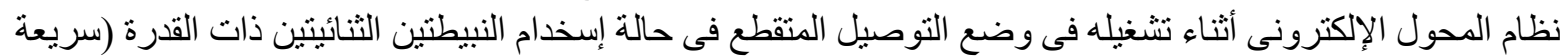

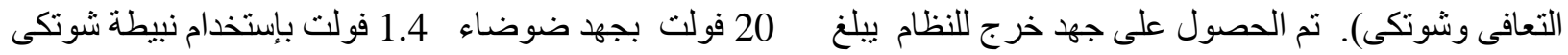

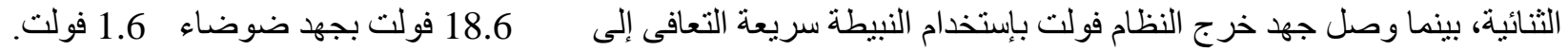

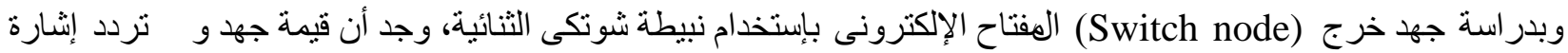

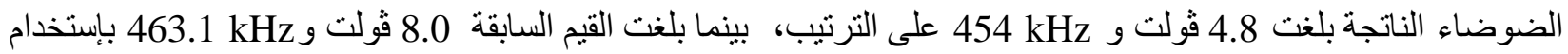

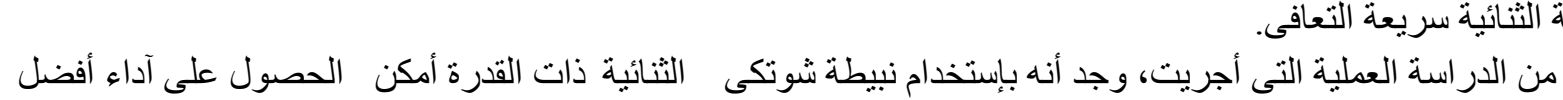

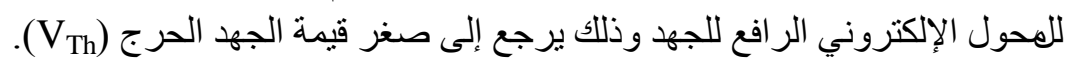

